\title{
Highly sensitive label-free colorimetric sensing of nitrite based on etching of gold nanorods $\dagger$
}

\author{
Zhaopeng Chen, ${ }^{* a}$ Zhiyang Zhang, ${ }^{a b}$ Chengli Qu, ${ }^{a}$ Dawei $\operatorname{Pan}^{a}$ and Lingxin Chen $* a$ \\ Received 12th June 2012, Accepted 1st September 2012 \\ DOI: 10.1039/c2an35787a
}

\begin{abstract}
A simple colorimetric method with high sensitivity and selectivity was developed for sensing of nitrite as low as $4.0 \mu \mathrm{M}$ by naked eyes, which is based on etching of gold nanorods accompanied by shape changes in aspect ratios (length/width) and a visible color change from bluish green to red and then to colorless with the increase of nitrite.
\end{abstract}

As type A inorganic contaminants in drinking water, nitrite and nitrate have proven to be of great threat to human health and may result in diseases like methemoglobinemia, esophageal cancer, etc. ${ }^{1-3}$ Many methods, such as ion chromatography, ${ }^{4}$ capillary electrophoresis, ${ }^{5}$ chemiluminescence ${ }^{6}$ and fluorescence spectrum, ${ }^{7}$ have been developed for the detection of $\mathrm{NO}_{2}{ }^{-}$and $\mathrm{NO}_{3}{ }^{-}$. However, all these methods have poor applicability to field tests. As the largest developing country, China is encountering a great drinking water crisis resulting from the worsening quality of source water. The situation is even worse in its rural regions where people mainly rely on simply prepared tap water or even untreated surface water, shallow groundwater, cellar water, etc. The concentrations of $\mathrm{NO}_{2}{ }^{-}$and $\mathrm{NO}_{3}{ }^{-}$in most of such water may have reached dangerous level ${ }^{8-10}$ and have barely been monitored due to the lack of funds, equipments and qualified persons. It is urgent to develop a simple test method that can be quickly handled by local inhabitants.

Colorimetric assays have proven to be effective for the inspection of $\mathrm{NO}_{2}{ }^{-}$in food and wastewater. ${ }^{11-13}$ It is unfortunate that photoabsorption coefficients of employed organic dyes are rather low, which withhold further applications of most colorimetric assays in the quality assurance of drinking water. Benefiting from high photoabsorption coefficients, nano-materials have been widely applied in colorimetric assays for the detection of various targets, ${ }^{14-23}$ as well as $\mathrm{NO}_{2}{ }^{-}$in drinking water. ${ }^{24,25}$ The first attempt was made by Mirkin et $a .^{25}$ based on the induced aggregation of two kinds of

${ }^{a}$ Key Laboratory of Coastal Zone Environmental Processes, Yantai Institute of Coastal Zone Research (YIC), Chinese Academy of Sciences (CAS), Shandong Provincial Key Laboratory of Coastal Zone Environmental Processes, YICCAS, Yantai, Shandong 264003, P. R. China.E-mail: zhpchen@yic.ac.cn; lxchen@yic.ac.cn; Fax: +86 535 2109133; +86 535 2109130; Tel: +86 535 2109133; +865352109130

${ }^{b}$ Graduate University of Chinese Academy of Sciences, Beijing 100049, China

$\dagger$ Electronic supplementary information (ESI) available: Fig. S1-S3 and optimization of experimental conditions. See DOI: 10.1039/c2an35787a functionalized gold nanoparticles (GNPs). Their method yielded a detection limit of $22 \mu \mathrm{M} \mathrm{NO}_{2}^{-}$by naked eyes. Thereafter, using 4-aminothiophenol modified gold nanorods (GNRs) as a color producing-reagent, $\mathrm{Yu}$ and $\mathrm{Xiao}^{24}$ developed a non-crosslinking colorimetric $\mathrm{NO}_{2}{ }^{-}$sensor based on deamination reaction induced by $\mathrm{NO}_{2}{ }^{-}$which resulted in the GNRs aggregation. This method yielded a detection limit of about $10 \mu \mathrm{M}$ for $\mathrm{NO}_{2}{ }^{-}$within 10 minutes. The above attempts suggested nano-materials as a promising regulator in the sensing of $\mathrm{NO}_{2}{ }^{-}$in drinking water by colorimetric assays. The methods will be more practical if related processes are simplified and detection ranges are extended.

Herein we developed a much simpler label-free colorimetric method for sensing of $\mathrm{NO}_{2}^{-}$based on etching of GNRs. Its applicability, as tested, is suitable for the detection of $\mathrm{NO}_{2}{ }^{-}$as low as $4.0 \mu \mathrm{M}$ by naked eyes.

As shown in Scheme 1, the solution of GNRs (length/diameter ratio about $1.3: 1$ ) appeared bluish green owing to the intense longitudinal surface plasmon resonance (SPR) absorption of GNRs around $630 \mathrm{~nm}$. The addition of $10 \mu \mathrm{M} \mathrm{NO}_{2}{ }^{-}$to the colloidal solution caused a color change from bluish green to red within 20 minutes. More $\mathrm{NO}_{2}^{-}(40 \mu \mathrm{M})$ caused the solution to be almost colorless. The progressive color change corresponds to the partial to complete dissolution of GNRs.

To confirm the dissolution of GNRs caused by $\mathrm{NO}_{2}{ }^{-}$, the absorption spectra of GNRs after incubation in $\mathrm{NO}_{2}{ }^{-}$solutions $(\mathrm{pH} \approx 0)$ at different intervals were examined. As shown in Fig. 1, the absorption spectrum of GNRs (curve a) exhibited strong SPR absorption at bands of 530 and $630 \mathrm{~nm}$ corresponding to the

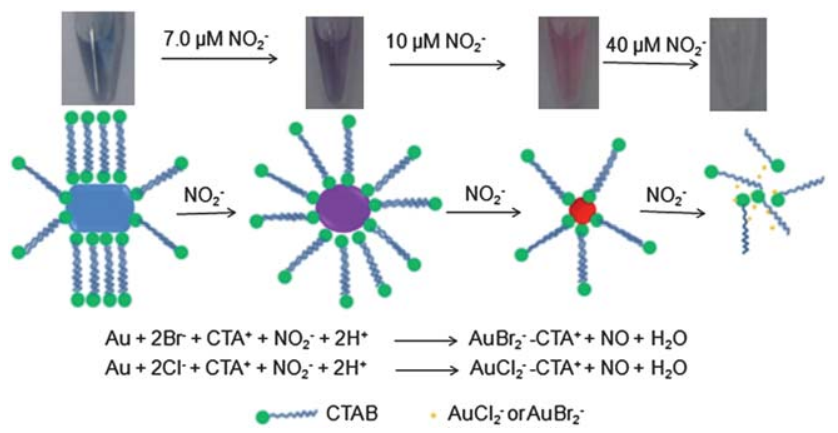

Scheme 1 Schematic illustration for the colorimetric sensing of $\mathrm{NO}_{2}^{-}$ based on etching of GNRs. 


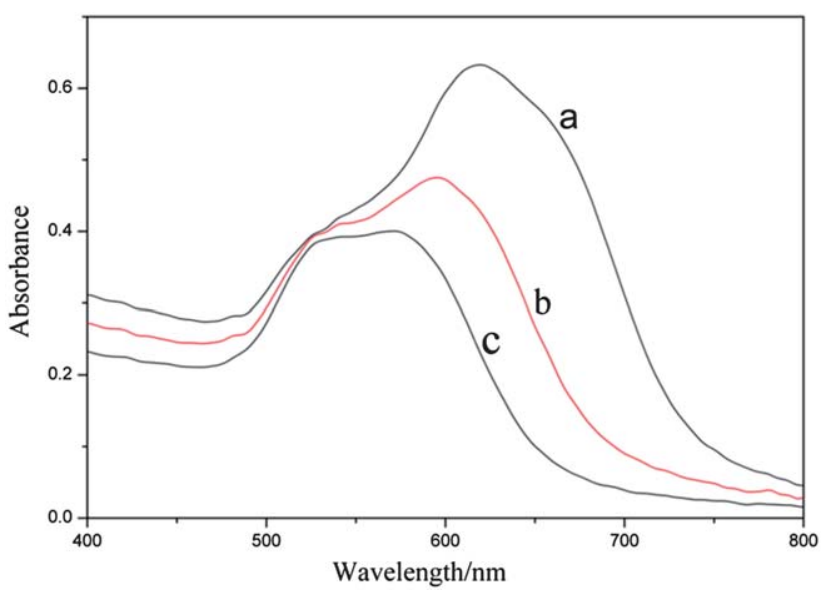

Fig. 1 Absorption spectra of GNRs after incubation with $10 \mu \mathrm{M} \mathrm{NO}_{2}{ }^{-}$ for (a) 0 , (b) 3, and (c) $10 \mathrm{~min}$, respectively.

transverse and longitudinal SPR absorption, respectively. The absorption band at $630 \mathrm{~nm}$ gradually bleached and shifted to short wavelength (curves $b$ and $c$ ) with the further dissolution of GNRs. Our results, together with those of Yang ${ }^{26}$ and Stucky, ${ }^{27}$ suggest that the blue-shift should be attributed to the decrease of aspect ratios (length/width) of GNRs and a preferential shortening along the axial direction. The difference between TEM images before and after incubation of GNRs with $\mathrm{NO}_{2}^{-}$(Fig. 2) showed that GNRs were transformed from rods into spherical particles, indicating that GNRs were progressively etched by $\mathrm{NO}_{2}^{-}$.

At $\mathrm{pH}=0$, the practical redox potential of $\mathrm{HNO}_{2} / \mathrm{NO}$ is $1.0 \mathrm{~V}$, while the standard redox potentials of $\mathrm{AuCl}_{2}{ }^{-} / \mathrm{Au}, \mathrm{AuCl}_{4}{ }^{-} / \mathrm{Au}$, $\mathrm{AuBr}_{2}{ }^{-} / \mathrm{Au}$ and $\mathrm{AuBr}_{4}{ }^{-} / \mathrm{Au}$ are 1.15, 1.00, 0.85, and $0.93 \mathrm{~V}$ relative to a standard hydrogen electrode (NHE), respectively. The thermodynamic differences theoretically suggest that gold can be oxidized to $\mathrm{AuBr}_{4}{ }^{-}$or $\mathrm{AuBr}_{2}{ }^{-}$by $\mathrm{NO}_{2}{ }^{-}$under similar conditions, although no direct evidence was reported. However, it was reported that gold could be leached in the presence of certain sulfur-containing chemicals and oxidants. ${ }^{28-30}$ The leaching was based on the formation of a $\mathrm{Au}^{+}$-sulfur-containing chemical complex which reduced the activity of $\mathrm{Au}^{+}$and therefore reduced the redox potential of $\mathrm{Au}^{+} / \mathrm{Au}$. Other research showed that cetyl trimethylammonium bromide (CTAB) could also reduce the activity of $\mathrm{AuBr}_{2}{ }^{-}$by the formation of a $\mathrm{AuBr}_{2}{ }^{-}-\mathrm{CTA}^{+}$complex and consequently reduce the redox potentials of $\mathrm{AuBr}_{2}{ }^{-} / \mathrm{Au}$ or $\mathrm{AuCl}_{2}{ }^{-} / \mathrm{Au}$ to less than $0.4 \mathrm{~V}$ relative to

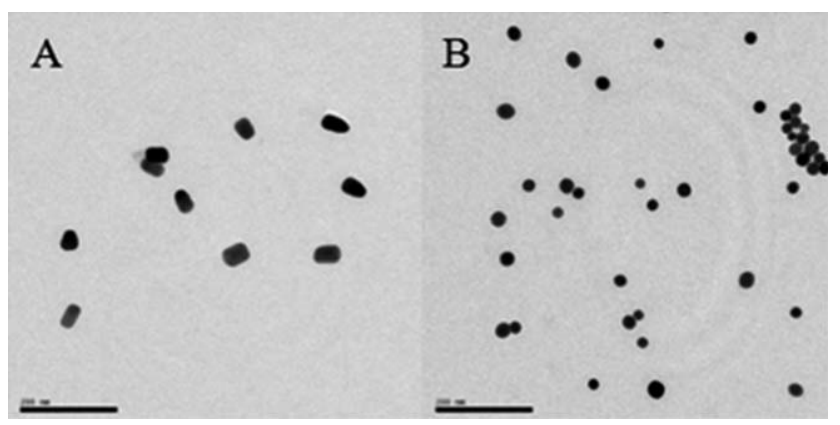

Fig. 2 TEM images of GNRs (A) before and (B) after incubation with $20 \mu \mathrm{M} \mathrm{NO}_{2}^{-}$.
NHE. ${ }^{31}$ Theoretically, the presence of CTAB could promote the redox reaction between gold and $\mathrm{NO}_{2}{ }^{-}$. To verify the fact, the following experiments were conducted. Gold nanoparticles (GNPs) were first stabilized by $0.4 \%$ Tween-20 to stabilize them in $1.0 \mathrm{M} \mathrm{HCl}$. Under such conditions, negligible difference of the absorption spectra of GNPs was observed with the coexistence of $1.0 \mathrm{mM} \mathrm{NO}_{2}^{-}$and $\mathrm{NaBr}$ (Fig. 3, curves a-d). It indicates that $\mathrm{Br}^{-}$did not promote the redox reaction between gold and $\mathrm{NO}_{2}{ }^{-}$. In contrast, the addition of CTAB would result in dramatic decrease of the absorbance of GNPs (Fig. 3, curves e-g), suggesting that the etching of GNRs by $\mathrm{NO}_{2}{ }^{-}$ was accelerated by CTAB. Since $\mathrm{AuCl}_{4}{ }^{-}$can oxidize Au to produce a $\mathrm{AuBr}_{2}{ }^{-}-\mathrm{CTA}^{+}$and/or $\mathrm{AuCl}_{2}{ }^{-}-\mathrm{CTA}^{+}$complex in the presence of $\mathrm{CTAB},{ }^{31}$ we presume that the GNRs were also oxidized to $\mathrm{AuBr}_{2}{ }^{-}$ $\mathrm{CTA}^{+}$and/or $\mathrm{AuCl}_{2}{ }^{-}-\mathrm{CTA}^{+}$instead of a $\mathrm{Au}(\mathrm{III})$ complex.

The absorption band at $630 \mathrm{~nm}$ gradually bleached and shifted to short wavelength, which indicated that the chemical etching of GNRs by $\mathrm{NO}_{2}{ }^{-}$is not isotropic in all directions. The preferential shortening along the axial direction can be attributed to less surface passivation and/or higher reaction activities at the tips of gold nanorods. ${ }^{32}$

To evaluate whether this response is selective toward $\mathrm{NO}_{2}{ }^{-}$, the influence of other common ions was investigated. As shown in the inset of Fig. 4, among the tested ions, $\mathrm{NO}_{2}{ }^{-}$and $\mathrm{Fe}^{3+}$ caused obvious color changes. The decrease of absorption areas from 480 to $840 \mathrm{~nm}$ $\left(\right.$ Area $_{\text {blank }}-$ Area $_{\text {sample }}$ ) of GNRs after incubation with such ions $\left(100 \mu \mathrm{M}\right.$ except for $\mathrm{Cu}^{2+}$ and $\left.\mathrm{Fe}^{3+}, 10 \mu \mathrm{M}\right)$ served as another reference. $\mathrm{NO}_{3}{ }^{-}, \mathrm{PO}_{4}{ }^{3+}, \mathrm{Ac}^{-}, \mathrm{Br}^{-}, \mathrm{SCN}^{-}, \mathrm{ClO}_{4}^{-}, \mathrm{S}^{2-}, \mathrm{Pb}^{2+}, \mathrm{Hg}^{2+}$, $\mathrm{Ca}^{2+}, \mathrm{Al}^{3+}, \mathrm{Mn}^{2+}, \mathrm{Ag}^{+}, \mathrm{Cr}^{3+}, \mathrm{Cu}^{2+}$ and $\mathrm{Cd}^{2+}$ gave almost no response. A slight decrease was observed for $\mathrm{SO}_{4}{ }^{2-}$ and $\mathrm{Zn}^{2+} \cdot \mathrm{Mg}^{2+}$ likely inhibited the oxidation of GNRs by dissolved oxygen and caused a slight increase (GNRs would be partially dissolved at a certain extent of oxygen, see Fig. S1 in the ESI $\dagger$ ). At identical concentrations, $\mathrm{NO}_{2}^{-}$and $\mathrm{Fe}^{3+}(10 \mu \mathrm{M})$ presented remarkable responses. $\mathrm{Fe}^{3+}$ can also oxidize GNRs and lead to an absorption spectrum change of GNRs, which would interfere with the sensing of $\mathrm{NO}_{2}{ }^{-32}$ The interference of $\mathrm{Fe}^{3+}$ could be eliminated by the addition of $0.01 \mathrm{M}$ 1,2-cyclohexylenedinitrilotetraacetic acid (DCTA) to form

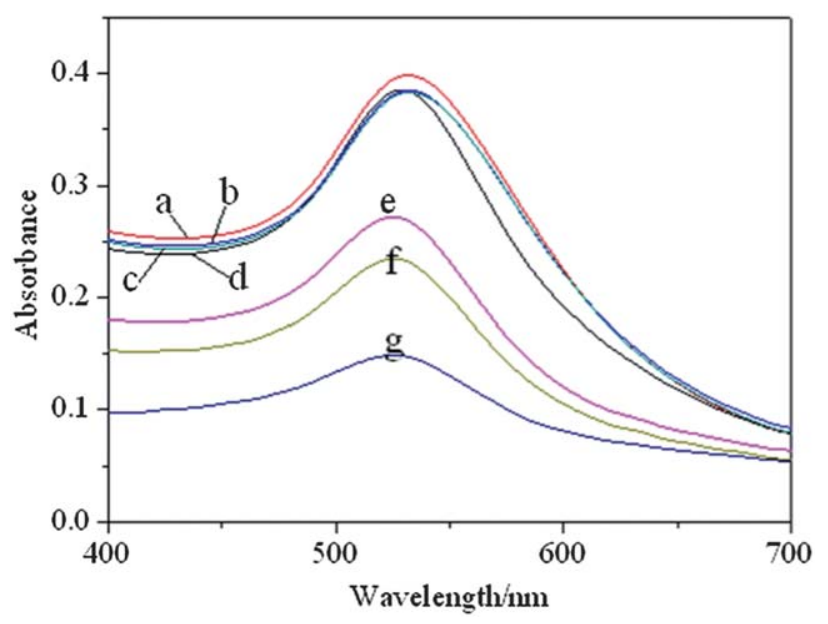

Fig. 3 The absorption spectra of GNPs after incubation with $0.1 \mathrm{mM}$ $\mathrm{NO}_{2}{ }^{-}$(a), $0.1 \mathrm{mM} \mathrm{NO}_{2}{ }^{-}+4 \mathrm{mM} \mathrm{Br}^{-}$(b), $0.1 \mathrm{mM} \mathrm{NO}_{2}{ }^{-}+5 \mathrm{mM} \mathrm{Br}^{-}$(c), $0.1 \mathrm{mM} \mathrm{NO}_{2}^{-}+6 \mathrm{mM} \mathrm{Br}^{-}$(d), $0.1 \mathrm{mM} \mathrm{NO}_{2}^{-}+4 \mathrm{mM} \mathrm{CTAB}(\mathrm{e})$,

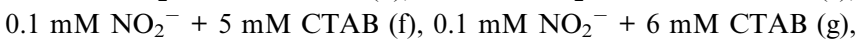
respectively. 


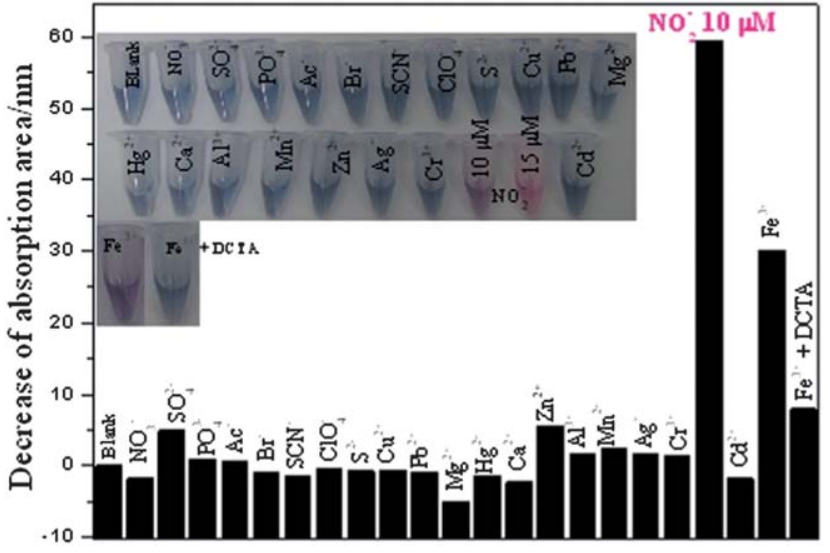

Fig. 4 Decrease of absorption areas and color changes of tested solutions for common ions at $100 \mu \mathrm{M}$ (except $\mathrm{Cu}^{2+}, \mathrm{Fe}^{3+}$ and $\left.\mathrm{NO}_{2}^{-}, 10 \mu \mathrm{M}\right)$.

a complex of DCTA- $\mathrm{Fe}^{3+}$ and reduce the reaction activity of $\mathrm{Fe}^{3+}$ (the conditional stability constant $K_{\text {FeDCTA }}{ }^{\prime}$ is $10^{6.24}$ ). The present system provides excellent selectivity for $\mathrm{NO}_{2}{ }^{-}$over other ions in the presence of $0.01 \mathrm{M}$ DCTA. It should be attributed to the relatively high redox potential of $\mathrm{AuBr}_{4}{ }^{-}-\mathrm{CTA}^{+} / \mathrm{Au}$ which excludes the oxidation of GNRs by other common ions.

Fig. 5 shows the analytical performance of our proposed method. The absorption area of GNRs decreased gradually with the increase of $\mathrm{NO}_{2}{ }^{-}$. Under optimal conditions ( $\mathrm{pH} \approx 0$, incubation temperature $55^{\circ} \mathrm{C}$, incubation time $20 \mathrm{~min}$, see Optimization of experimental conditions section in the ESI, $\uparrow$ Fig. S1-S3), a good linear relationship

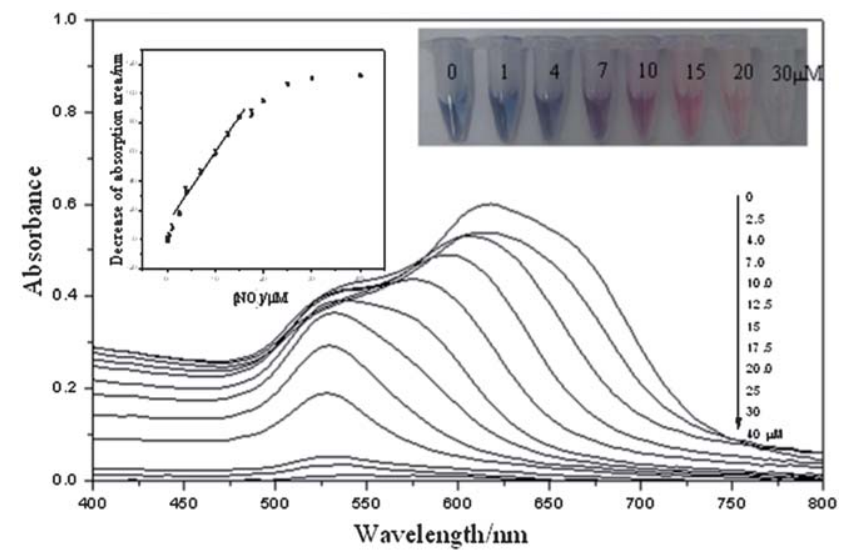

Fig. 5 Absorption spectra of GNRs after incubation with different concentrations of $\mathrm{NO}_{2}^{-}$for $20 \mathrm{~min}$. Insets show the decrease of absorption area response to different concentrations of $\mathrm{NO}_{2}{ }^{-}$and the colour change with the increase of $\mathrm{NO}_{2}{ }^{-}$concentration from left to right, respectively.

Table 1 The recovery of spiked $\mathrm{NO}_{2}{ }^{-}$in local drinking water. The standard deviation of each sample was obtained by three measurements

\begin{tabular}{lcllc}
\hline Sample & Added $(\mu \mathrm{M})$ & Detected $(\mu \mathrm{M})$ & RSD $(\%)$ & Recovery $(\%)$ \\
\hline 1 & 2.50 & 2.62 & 0.9 & 104.6 \\
2 & 4.00 & 3.77 & 2.8 & 94.2 \\
3 & 7.00 & 5.41 & 1.0 & 77.3 \\
4 & 10.0 & 7.56 & 1.0 & 75.6 \\
\hline
\end{tabular}

between the decrease of absorption area from 400 to $800 \mathrm{~nm}$ (Area blank - Area sample$_{\text {le }}$ and $\mathrm{NO}_{2}{ }^{-}$concentrations was obtained within the range of 1.0 to $15.0 \mu \mathrm{M}(R=0.997)$. The detection limit was calculated to be $0.5 \mu \mathrm{M}\left(23 \mu \mathrm{g} \mathrm{L}^{-1}, S / N=3\right)$, which is far below the maximum containment level as recommended by U.S. EPA ( $1 \mathrm{mg} \mathrm{L}{ }^{-1}$ measured as nitrogen, $\sim 71 \mu \mathrm{M}$ for $\left.\mathrm{NO}_{2}{ }^{-}\right) .{ }^{24}$ The digital photo in the inset of Fig. 3 indicates that a containment level of $4.0 \mu \mathrm{M}\left(184 \mu \mathrm{g} \mathrm{L}^{-1}\right)$ can be easily read out by naked eyes.

The practical performance of the proposed method was further tested by samples of local drinking water. $\mathrm{No} \mathrm{NO}_{2}{ }^{-}$was detected in such samples. The method was alternatively tested by standard addition and the recovery of spiked $\mathrm{NO}_{2}{ }^{-}$ranges from 75.6 to $104.6 \%$ (Table 1). It indicates that such a method is applicable to the quantification of $\mathrm{NO}_{2}^{-}$in aqueous solutions.

In summary, this study reported a new convenient colorimetric method for the detection of $\mathrm{NO}_{2}^{-}$based on the etching of GNRs. The method is characterized by its high selectivity and sensitivity, with a considerably low detection limit of $56 \mu \mathrm{g} \mathrm{L}^{-1}$ (measured as nitrogen). The method is more sensitive and simpler compared with those proposed by Mirkin et al. ${ }^{25}$ and $\mathrm{Yu}$ and Xiao. ${ }^{24}$ The highlight of this method is the obvious visible color change of GNR solutions correlated to different concentrations of $\mathrm{NO}_{2}^{-}$. Hence, it is particularly applicable to field tests and can be expected to be further developed into economical products (e.g. $\mathrm{NO}_{2}{ }^{-}$test-papers). Since $\mathrm{NO}_{3}{ }^{-}$can be easily reduced to $\mathrm{NO}_{2}{ }^{-}$by enzyme or metallic catalysts, the proposed colorimetric assays for nitrite can be used for nitrate detection, theoretically.

The research was financially supported by the Department of Science and Technology of Shandong Province (BS2009DX006, 2008GG20005005), NSFC (no. 21275158, 21007087), CAS (KZCX2YW-JS208) and the 100 Talents Program of the CAS.

\section{Notes and references}

1 B. Aschebrook-Kilfoy, A. J. Cross, R. Z. Stolzenberg-Solomon, A. Schatzkin, A. R. Hollenbeck, R. Sinha and M. H. Ward, Am. J. Epidemiol., 2011, 174, 305.

2 C. G. Kevil and D. J. Lefer, Cardiovasc. Res., 2011, 89, 489.

3 B. A. Kilfoy, Y. Zhang, Y. Park, T. R. Holford, A. Schatzkin, A. Hollenbeck and M. H. Ward, Int. J. Cancer, 2011, 129, 160.

4 Y. Li, J. S. Whitaker and C. L. McCarty, J. Chromatogr., A, 2011, 1218, 476.

5 A. Gaspar, P. Juhasz and K. Bagyi, J. Chromatogr., A, 2005, 1065, 327.

6 Z. Lin, W. Xue, H. Chen and J. M. Lin, Anal. Chem., 2011, 83, 8245.

7 T. Zhang and C. Li, Luminescence, 2008, 23, 109.

8 H. Yu, H. Luo, X. Lu, Q. Song and Z. Fan, Zhonghua Liuxingbingxue Zazhi, 2002, 23, 419.

9 L.-F. Du, T.-K. Zhao, C.-J. Zhang, Z.-Z. An, Q. Wu, B.-C. Liu, P. Li and M.-T. Ma, Agric. Sci. China, 2011, 10, 423.

10 W. L. Zhang, Z. X. Tian, N. Zhang and X. Q. Li, Agric., Ecosyst. Environ., 1996, 59, 223.

11 A. D. Beaton, V. J. Sieben, C. F. A. Floquet, E. M. Waugh, S. A. K. Bey, I. R. G. Ogilvie, M. C. Mowlem and H. Morgan, Sens. Actuators, B, 2011, 156, 1009.

12 W. D. Gong, M. Mowlem, M. Kraft and H. Morgan, IEEE Sens. J., $2009,9,862$

13 V. J. Sieben, C. F. A. Floquet, I. R. G. Ogilvie, M. C. Mowlem and H. Morgan, Anal. Methods, 2010, 2, 484.

14 Y. Y. Chen, C. W. Tseng, H. Y. Chang, Y. L. Hung and C. C. Huang, Biosens. Bioelectron., 2011, 26, 3160.

15 J. R. Woo, D. K. Lim and J. M. Nam, Small, 2011, 7, 648.

16 P. He, L. Shen, R. Liu, Z. Luo and Z. Li, Anal. Chem., 2011, 83, 6988.

17 N. Nath and A. Chilkoti, Anal. Chem., 2002, 74, 504.

18 L.-J. Ou, P.-Y. Jin, X. Chu, J.-H. Jiang and R.-Q. Yu, Anal. Chem., 2010, 82, 6015. 
19 J. H. Lee, Z. Wang, J. Liu and Y. Lu, J. Am. Chem. Soc., 2008, 130, 14217.

20 O. R. Miranda, X. Li, L. Garcia-Gonzalez, Z.-J. Zhu, B. Yan, U. H. F. Bunz and V. M. Rotello, J. Am. Chem. Soc., 2011, 133, 9650.

21 R. A. Reynolds, C. A. Mirkin and R. L. Letsinger, J. Am. Chem. Soc., 2000, 122, 3795.

22 J. J. Storhoff, R. Elghanian, R. C. Mucic, C. A. Mirkin and R. L. Letsinger, J. Am. Chem. Soc., 1998, 120, 1959.

23 X. Xue, F. Wang and X. Liu, J. Am. Chem. Soc., 2008, 130, 3244.

24 N. Xiao and C. Yu, Anal. Chem., 2010, 82, 3659.

25 W. L. Daniel, M. S. Han, J. S. Lee and C. A. Mirkin, J. Am. Chem. Soc., 2009, 131, 6362.
26 R. Zou, X. Guo, J. Yang, D. Li, F. Peng, L. Zhang, H. Wang and H. Yu, CrystEngComm, 2009, 11, 2797.

27 C. K. Tsung, X. S. Kou, Q. H. Shi, J. P. Zhang, M. H. Yeung, J. F. Wang and G. D. Stucky, J. Am. Chem. Soc., 2006, 128, 5352.

28 D. Feng and J. S. J. van Deventer, Hydrometallurgy, 2011, 106, 38.

29 X. Yang, M. S. Moats, J. D. Miller, X. Wang, X. Shi and H. Xu, Hydrometallurgy, 2011, 106, 58.

30 D. Feng and J. S. J. van Deventer, Hydrometallurgy, 2010, 105, 120.

31 J. Rodriguez-Fernandez, J. Perez-Juste and L. M. Liz-Marzán, J. Phys. Chem. B, 2005, 109, 14257.

32 R. Zou, X. Guo, J. Yang, D. Li, F. Peng, L. Zhang, H. Wang and H. Yu, CrystEngComm, 2009, 11, 2797. 